\title{
Role of the neural pathway from hindbrain to hypothalamus in interaction of GLP1 and leptin in rats
}

\author{
Sayaka Akieda-Asai, Paul-Emile Poleni, Kazuya Hasegawa and Yukari Date \\ Frontier Science Research Center, University of Miyazaki, Miyazaki 889-1692, Japan
}

Correspondence should be addressed to $Y$ Date

Email

dateyuka@

med.miyazaki-u.ac.jp

\begin{abstract}
Glucagon-like peptide-1 (GLP1) and leptin are anorectic hormones. Previously, we have shown that i.p. coadministration of subthreshold GLP1 with leptin dramatically reduced food intake in rats. In this study, by using midbrain-transected rats, we investigated the role of the neural pathway from the hindbrain to the hypothalamus in the interaction of GLP1 and leptin in reducing food intake. Food intake reduction induced by coinjection of GLP1 and leptin was blocked in midbrain-transected rats. These findings indicate that the ascending neural pathway from the hindbrain plays an important role in transmitting the anorectic signals provided by coinjection of GLP1 and leptin.
\end{abstract}

$\begin{aligned} & \text { Key Words } \\ & \text { food intake } \\ & \text { - GLP1 } \\ & \text { leptin } \\ & \text { - midbrain transection }\end{aligned}$

Journal of Endocrinology (2014) 220, 109-116

\section{Introduction}

Leptin, an anorectic hormone produced by white adipose tissue, plays an important role in the maintenance of energy balance (Schwartz et al. 2000). The absence of leptin results in severe obesity in both rodents and humans (Pelleymounter et al. 1995, Farooqi et al. 1998). Leptin directly binds to its obesity receptor $\mathrm{b}(\mathrm{ObRb})$ receptors, which are located mainly in the hypothalamus and hindbrain; it promotes energy expenditure by stimulating JAK/STAT3 signaling pathway (Bjorbaek \& Kahn 2004). Leptin also inhibits AMP-activated protein kinase (AMPK) activity in the arcuate nucleus and in the paraventricular nucleus of the hypothalamus (Minokoshi et al. 2004).

Glucagon-like peptide-1 (GLP1), a gastrointestinal hormone produced by L cells in the distal small intestine and colon, is released in response to meal intake and ingested nutrients (Mojsov et al. 1986, Holst 2007). Because GLP1 and its receptors are present in both the CNS and peripheral tissues such as pancreatic $\beta$ cells and vagal afferents, the effect of GLP1 on energy metabolism could be mediated at central sites, peripheral sites, or both (Holst 2007, Hayes et al. 2010). Indeed, GLP1 reduces food intake after either central or peripheral administration (Williams et al. 2006).

Several gastrointestinal hormones associated with feeding and energy metabolism are not only transported to the brain via the circulation - they also modulate vagal afferent pathways (Date et al. 2006). The effects of peripheral GLP1, cholecystokinin (CCK), peptide YY (PYY), or ghrelin on feeding are blocked in vagotomized rats (Date et al. 2002, Koda et al. 2005). Vagal afferents reach the nucleus of the solitary tract (NTS) in the hindbrain, which contains the area postrema where the blood-brain barrier is circumvented. Thus, the hindbrain is an important site for integrating information from both the vagal afferent pathway and the circulation.

Recently, we have shown that i.p. coinjection of subthreshold GLP1 and leptin, which individually have no effect on feeding, dramatically reduced food intake by

Published by Bioscientifica Ltd. 
acting on the proopiomelanocortin (POMC)/melanocortin-4-receptor (MC4R) system. We have also found that coinjection of GLP1 and leptin decreases phosphorylated AMPK levels in the hypothalamus (Poleni et al. 2012). However, the site at which information from subthreshold GLP1 and that from subthreshold leptin become primarily integrated remains unclear.

A bilateral transection of the midbrain surgically cuts the neural pathways from the hindbrain to the hypothalamus (Date et al. 2006). Midbrain-transected rats are therefore useful for investigating whether information from subthreshold doses of GLP1 and leptin is integrated in the hypothalamus or hindbrain. In this study, by using midbrain-transected rats, we examined the effect of coinjection of GLP1 and leptin on food intake, Pomc mRNA levels, and phosphorylation of AMPK. Our findings provide insights into the physiological control of feeding systems by peripheral hormones.

\section{Materials and methods}

\section{Experimental animals}

Male Wistar rats (10 weeks old; Charles River Japan, Shiga, Japan) weighing 300-350 g were used for all experiments. Rats were given standard laboratory chow and water and allowed to feed and drink ad libitum. They were housed individually in plastic cages at a constant room temperature in a $12 \mathrm{~h}$ light: $12 \mathrm{~h}$ darkness cycle (0800-2000 h light).

After the rats were anesthetized with an i.p. injection of sodium pentobarbital (40 mg/kg; Abbot Laboratories), bilateral midbrain transections were performed as described previously (Crawley et al. 1984). In brief, the head was fixed in a stereotaxic instrument in a 2.4-mm-nose-down position. A steel knife blade of $1.5 \mathrm{~mm}$ wide was used to penetrate the brain in a coronal plane at two points: $0.5 \mathrm{~mm}$ on either side of the midline and $1 \mathrm{~mm}$ in front of the lambdoid suture. At each incision, the blade penetrated to a depth of $7.7 \mathrm{~mm}$ below the dura. In the sham operation, the skull was exposed but the brain was left intact. Only rats that exhibited increased weight gain and food intake were selected for subsequent feeding experiments. To confirm that the transection surgery had been successful, we removed the brains after the feeding tests and histologically verified the exact locations of the lesions.

All procedures were performed in accordance with the Japanese Physiological Society's guidelines for animal care. Our experimental protocol was approved by the Ethics Review Committee for Animal Experimentation of the Faculty of Medicine, University of Miyazaki, Japan.

\section{Feeding experiments}

Feeding experiments were conducted in midbraintransected rats 1 week after surgery. Rats were sufficiently habituated to handling and i.p. injections before the experiments. To investigate the effect of GLP1 and leptin on food intake, we used a dosage of $10 \mathrm{nmol} / \mathrm{kg}$ GLP1 (7-36) amide (Peptide Institute, Osaka, Japan) and $18.8 \mathrm{nmol} / \mathrm{kg}$ rat recombinant leptin (Sigma Aldrich), neither of which decreased food intake when administered alone (Poleni et al. 2012). We allocated the sham-operated and midbrain-transected rats to four treatment groups: single injection of saline, single injection of GLP1 $(10 \mathrm{nmol} / \mathrm{kg})$, single injection of leptin $(18.8 \mathrm{nmol} / \mathrm{kg})$, and coinjection of GLP1 $(10 \mathrm{nmol} / \mathrm{kg})$ and leptin $(18.8 \mathrm{nmol} / \mathrm{kg})$. The hormones were administered i.p. at 0930-1000 $\mathrm{h}$ to rats that had been fasted overnight. We then measured food intake at $0.5,1$, and $2 \mathrm{~h}$ after injection.

\section{Immunohistochemistry}

Saline or GLP1 and leptin was injected i.p. into the rats in which a bilateral midbrain transection or sham surgery was performed ( $n=3$ per group) $2 \mathrm{~h}$ before transcardiac perfusion with a fixative containing $4 \%(\mathrm{w} / \mathrm{v})$ formaldehyde. The brains were removed and sectioned into $40-\mu \mathrm{m}$-thick samples. The regions of the hypothalamus were identified according to the information provided in the rat brain stereotaxic atlas of Paxinos \& Watson (2005). Immunohistochemistry was carried out with an anti-cFos antibody (Ab-5; Calbiochem, La Jolla, CA, USA; 1:10 000), as described previously (Date et al. 1999).

Some sections were used for double-labeling immunohistochemistry. They were first incubated with rabbit anti-cFos antibody (9F6; Cell Signaling Technology, Danvers, MA, USA; 1:500) and stained with Alexa Fluor 594-conjugated anti-rabbit IgG (Molecular Probes, Eugene, OR, USA; 1:200). We used 9F6 for the immunofluorescence staining because staining of cFos with Ab5 antibody produced weak and unclear results. Subsequently, these sections were incubated with anti- $\alpha$-melanocytestimulating hormone (MSH) antibody (Millipore, Tokyo, Japan; 1:10 000) and pre-labeled by using commercially available labeling kits (Fluorescein Labeling Kit- $\mathrm{NH}_{2}$; Dojindo, Kumamoto, Japan). Anti- $\alpha$-MSH antiserum was used to identify POMC-like immunoreactive neurons, as POMC is a precursor of $\alpha$-MSH. Images were viewed and captured with a Zeiss AX10 fluorescence microscope (Carl Zeiss, Oberkochen, Germany). Fos-positive cells were counted in five sections each of the hypothalamic arcuate

Published by Bioscientifica Ltd 
nucleus and paraventricular nucleus from each animal (Koda et al. 2005); Fos-expressing $\alpha$-MSH-positive cells in the hypothalamic arcuate nucleus were enumerated in the same manner.

\section{Quantitative PCR for POMC}

The hypothalami were rapidly removed $1.5 \mathrm{~h}$ after shamoperated or midbrain-transected rats received injections of saline or of GLP1 and leptin. Total RNAs were extracted with TRIzol Reagent (Invitrogen) and reversetranscribed by using a Superscript III First-Strand Synthesis System Kit (Invitrogen). We have previously demonstrated that Pomc mRNA expression significantly increases after coinjection of GLP1 and leptin (Poleni et al. 2012). Therefore, quantitative PCR was conducted for Pomc by using the hypothalami of midbrain-transected and sham-operated rats. Real-time PCR was conducted with a LightCycler system (Roche Diagnostics) and an SYBR Premix Ex Taq II Kit (Takara Bio, Otsu, Japan). The primer sequences used have been described elsewhere (Date et al. 2010). The relative abundances of all reaction products were normalized against the level of glyceraldehyde 3-phosphate dehydrogenase mRNA.

\section{Western blotting}

We have previously demonstrated that phosphorylation of AMPK in the hypothalamus significantly decreases after coinjection of GLP1 and leptin (Poleni et al. 2012). Therefore, in this study, we evaluated the level of phosphorylation of AMPK after coinjection of GLP1 and leptin into midbrain-transected rats. The hypothalami were rapidly removed $1.5 \mathrm{~h}$ after i.p. injection of saline or of GLP1 and leptin into sham-operated or midbrain-transected rats. Thirty micrograms of total protein per sample were analyzed by SDS-PAGE ( $8 \%$ acrylamide gel) and electroblotted onto polyvinylidene difluoride membranes (Immobilon-P; Millipore). The membranes were blocked for $1 \mathrm{~h}$ at room temperature with Blocking One-P (Nacalai Tesque, Kyoto, Japan), probed overnight at $4{ }^{\circ} \mathrm{C}$ with primary antibody against AMPK or phosphorylated AMPK (Cell Signaling Technology), and incubated for $1 \mathrm{~h}$ at room temperature with HRP-conjugated secondary antibodies (Epitomics, Burlingame, CA, USA). Specific proteins were detected by chemiluminescence with Western BLoT Quant HRP substrate (Takara Bio) in accordance with the manufacturer's instructions, and then exposed to X-ray film (Fuji Film, Tokyo, Japan). Western blotting was quantified by densitometry relative to AMPK by using
NIH Image J software (National Institute of Health, Bethesda, MA, USA).

\section{Statistical analysis}

All data are expressed as mean \pm s.E.M. Statistical significance was evaluated by using Student's $t$-test, one-way ANOVA (for group), or two-way repeated-measures ANOVA (for group and time). When the ANOVA indicated a significant effect of a variable of concern, differences between groups were analyzed by using the Tukey-Kramer post hoc test. $P<0.05$ was considered statistically significant.

\section{Results}

\section{Food intake}

Coinjection of GLP1 and leptin significantly decreased food intake 1 and $2 \mathrm{~h}$ after coinjection in sham-operated rats compared with sham-operated rats that had received injections of saline, whereas it did not reduce food intake in midbrain-transected rats (Fig. 1).

\section{Fos expression}

In sham-operated rats, coinjection of GLP1 and leptin significantly increased the number of Fos-positive cells relative to that after injection of saline in the

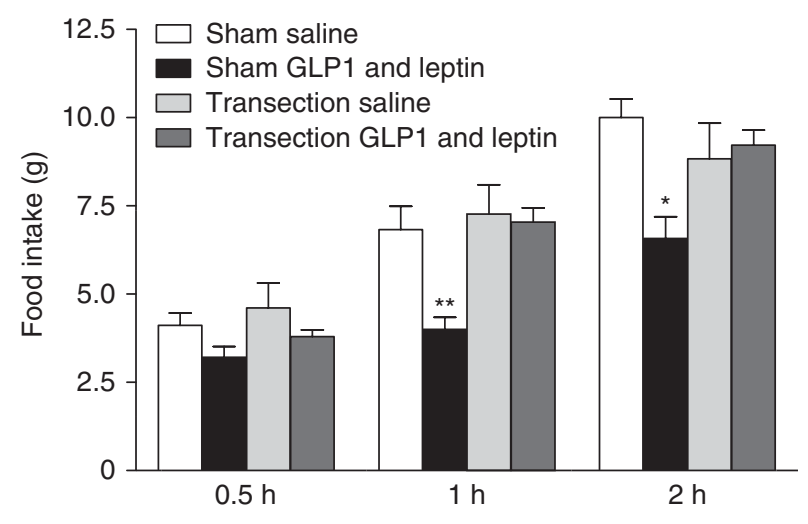

Figure 1

Effects of i.p. administration of saline or of GLP1 $(10 \mathrm{nmol} / \mathrm{kg})$ and leptin $(18.8 \mathrm{nmol} / \mathrm{kg})$ on food intake in sham-operated rats and midbraintransected rats. Data represent means and s.E.M. ( $n=8$ or 9 each). A significant interaction between group and time was determined by a two-way ANOVA for repeated measures $(P<0.05 ; F=2.74 ; \mathrm{df}=6)$. The Tukey-Kramer post-hoc test revealed significant differences in food intake between the sham-operated saline and sham-operated GLP-1 and leptin groups 1 and $2 \mathrm{~h}$ after injection. ${ }^{*} P<0.05$ vs sham-operated saline; $* * P<0.01$ vs sham-operated saline. 
hypothalamic arcuate nucleus (Fig. $2 \mathrm{~A}$ and $\mathrm{B}$ ) and paraventricular nucleus (Fig. $2 \mathrm{C}$ and D). In contrast, in both areas of midbrain-transected rats, the number of Fospositive cells after coinjection of GLP1 and leptin did not differ from that after saline injection (Fig. 2A, B, C, and D). Double immunohistochemistry for Fos and $\alpha$-MSH demonstrated that Fos was expressed in $62.2 \pm 5.5 \%$ of $\alpha$-MSH-immunoreactive neurons of the arcuate nucleus in the sham-operated rats after coinjection of GLP1 and leptin. In contrast, Fos was expressed in only $6.1 \pm 0.5 \%$ of $\alpha$-MSH-immunoreactive neurons in the midbraintransected rats after coinjection of GLP1 and leptin (Fig. 2E and $\mathrm{F}$ ). There were no significant differences in the number of $\alpha$-MSH-immunoreactive cells between sham-operated rats and midbrain-transected rats $(29.7 \pm 2.7$ and $33.5 \pm 2.6$ per section, respectively; data not shown).

\section{Pomc mRNA levels}

To examine the contribution of the neural pathway from the hindbrain to the hypothalamus to the increase in Pomc mRNA levels, we measured Pomc mRNA levels in the hypothalami of midbrain-transected rats. The Pomc mRNA level after coinjection of GLP1 and leptin into shamoperated rats was significantly higher than that after injection of saline, whereas no increase in Pomc mRNA expression after coinjection was found in the midbraintransected rats (Fig. 3).

\section{Phosphorylation of AMPK}

Phosphorylation of AMPK in the hypothalami of sham-operated rats was dramatically and significantly reduced after coinjection of GLP1 and leptin (Fig. 4). However, no reduction in AMPK phosphorylation occurred in the hypothalami of midbrain-transected rats after coinjection (Fig. 4).

\section{Discussion}

Food intake and energy metabolism are finely regulated by the complicated interaction of many factors. Recently, we have shown that a single i.p. injection of GLP1 at $10 \mathrm{nmol} / \mathrm{kg}$ or leptin at $18.8 \mathrm{nmol} / \mathrm{kg}$ never induces food intake reduction in rats, whereas coinjection of the two at these subthreshold doses dramatically reduces food intake (Poleni et al. 2012). Several hormones, including ghrelin, CCK, PYY, and GLP1, at least in part, use the vagal afferent pathway to transmit starvation or satiety signals to the brain (Stanley et al. 2005). The NTS of the hindbrain is the site of the first synaptic contact for vagal afferent projections from the gastrointestinal tract. The hindbrain also contains the area postrema, where the blood-brain barrier is circumvented. Thus the hindbrain is accessible to feeding signals not only through the vagal afferents but also directly via circulating hormones, including leptin. Indeed, we have confirmed the induction of phosphorylated STAT3 in the hindbrain after peripheral injection of leptin (data not shown). Some reports have also shown that peripheral leptin administration results in rapid induction of STAT3 phosphorylation in the NTS (Elias et al. 2000, Hosoi et al. 2002, Munzberg et al. 2003). In addition, the NTS has particularly high levels of ObRb expression (Leshan et al. 2006, Myers et al. 2009). These observations indicate that the hindbrain is involved in the interaction of GLP1 and leptin, which reduces food intake. In a previous study, we have also shown that coinjection of subthreshold doses of GLP1 and leptin significantly increased Pomc mRNA levels and decreased phosphorylation of AMPK in the hypothalamus (Poleni et al. 2012). These findings indicate that the signals caused by coinjection of GLP1 and leptin are ultimately integrated, at least in part, in the hypothalamus via the hindbrain and are responsible for reduced food intake.

In this study, we used midbrain-transected rats, in which the rostral pathway to the NTS was disrupted to investigate the role of the neural pathway from the hindbrain to the hypothalamus in the reduction of food intake induced by the interaction of GLP1 and leptin. Coinjection of subthreshold doses of GLP1 and leptin in midbrain-transected rats did not reduce food intake. This finding indicates that the neural pathway from the hindbrain to the hypothalamus is an important route involved in the food intake reduction induced by the interaction of GLP1 and leptin. Thus, satiety signals produced by coinjection of these hormones may reach the hindbrain and then be transmitted to the hypothalamus via certain neurotransmitters. A more complicated and sophisticated system is likely to integrate various signals in the hypothalamus. Further studies are needed to elucidate the relationship between neural circuits and the peripheral signals involved in feeding.

To investigate the hypothalamic nuclei that are activated by coinjection of GLP1 and leptin, we evaluated the expression pattern of Fos, an immediate early gene product associated with functionally activated neural circuits (Sagar et al. 1988, Chan et al. 1993). Fos expression in the hypothalamic arcuate nucleus or paraventricular nucleus was induced by coinjection of GLP1 and leptin in sham-operated rats, but not by a single administration of

Published by Bioscientifica Ltd. 
A

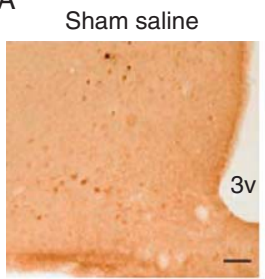

Sham GLP1 and leptin

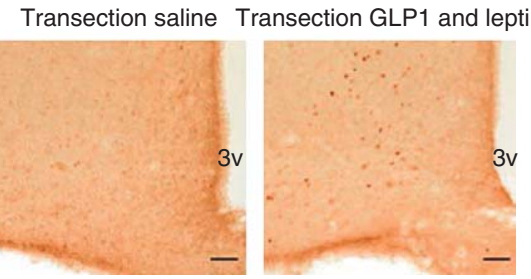

C

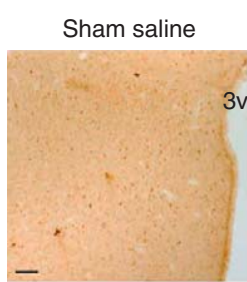

Transection saline
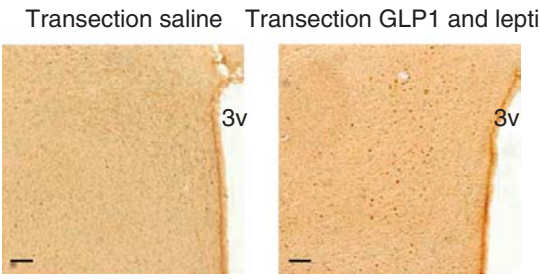

$E$

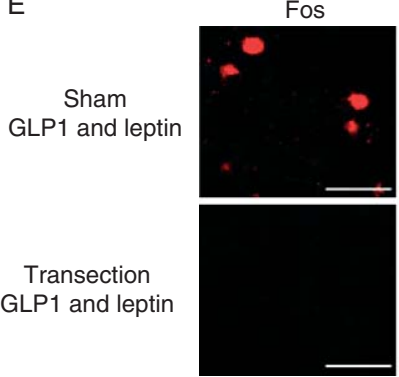

Sham GLP1 and leptin

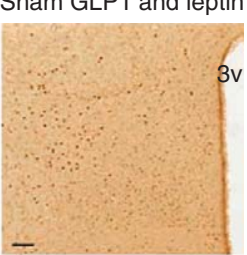

$\mathrm{D}$

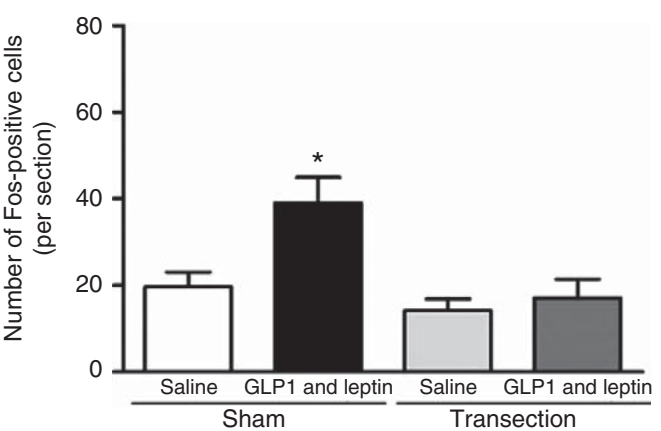

Figure 2

Localization of Fos expression following administration of saline, GLP1 $(10 \mathrm{nmol} / \mathrm{kg})$, leptin $(18.8 \mathrm{nmol} / \mathrm{kg})$, or GLP1 $(10 \mathrm{nmol} / \mathrm{kg})$ and leptin $(18.8 \mathrm{nmol} / \mathrm{kg})$ to rats receiving midbrain-transection or sham surgery. (A and C) Fos expression was determined in the hypothalamic arcuate nucleus (A) and paraventricular nucleus (C) of sham-operated rats and midbrain-transected rats after i.p. administration of saline or GLP1 + leptin. $3 \mathrm{~V}$, third ventricle; scale bar, $100 \mu \mathrm{m}$. (B and D) Number of Fos-positive cells in the arcuate nucleus (B) and paraventricular nucleus (D) of shamoperated rats and midbrain-transected rats after i.p. administration of saline or GLP1 + leptin. Data represent means \pm s.E.M. $(n=5$ each).
B
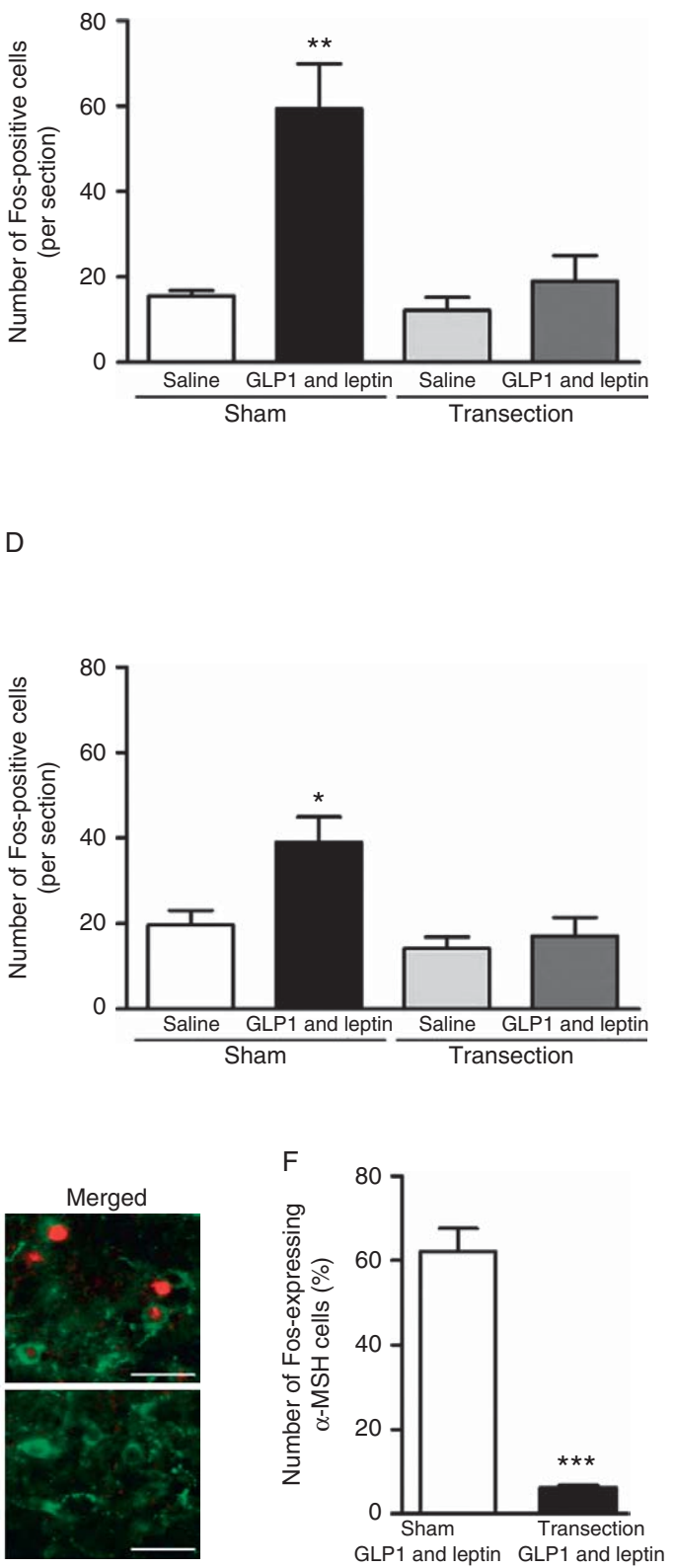

http://joe.endocrinology-journals.org DOI: $10.1530 / J O E-13-0272$
(C) 2014 Society for Endocrinology Printed in Great Britain
$* P<0.05$ vs sham-operated saline; $* * P<0.01$ vs sham-operated saline (one-way ANOVA followed by Tukey-Kramer test). (E) Double immunostaining with Fos (red) and $\alpha$-melanocyte-stimulating hormone (MSH, green) in the arcuate nucleus of sham-operated rats and midbraintransected rats after i.p. administration of saline or GLP1 + leptin. Scale bar: $50 \mu \mathrm{m}$. (F) Number of Fos-expressing $\alpha$-MSH cells in the arcuate nucleus in sham-operated rats and midbrain-transected rats after i.p. administration of GLP1 and leptin. Data represent means \pm s.E.M. ( $n=5$ each). $* * * P<0.001$ vs sham-operated GLP1 and leptin (Student's $t$-test). 


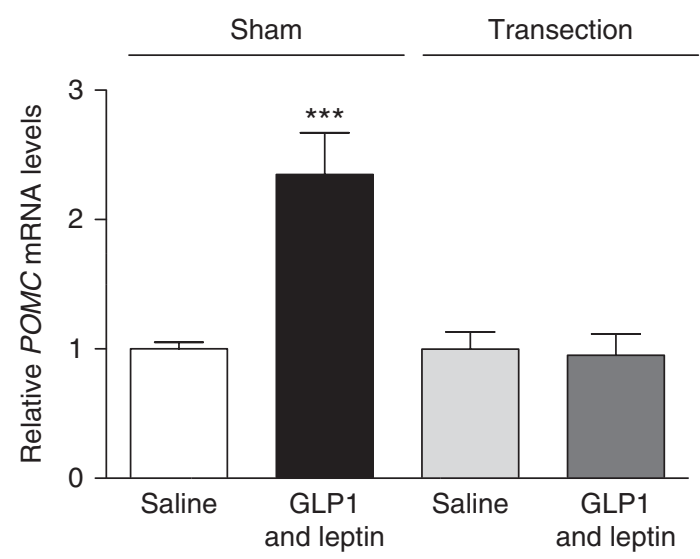

Figure 3

Quantitative polymerase chain reaction analysis of proopiomelanocortin $(P O M C)$ in the hypothalami of sham-operated rats and midbrain-transected rats after i.p. administration of saline or of GLP1 $(10 \mathrm{nmol} / \mathrm{kg})$ and leptin $(18.8 \mathrm{nmol} / \mathrm{kg})$. Data were normalized against the amount of glyceraldehyde 3-phosphate dehydrogenase. Data represent means \pm s.E.M. ( $n=5$ each). $* * * P<0.001$ vs sham-operated saline (one-way ANOVA followed by Tukey-Kramer test).

saline, GLP1, or leptin alone in sham-operated or midbrain-transected rats (data not shown). In contrast, coinjection of GLP1 and leptin in midbrain-transected rats did not induce Fos expression in either the arcuate nucleus or the paraventricular nucleus. Our double-immunostaining study showed that most of the $\alpha$-MSH-positive neurons of the arcuate nucleus in the sham-operated rats expressed Fos protein after coadministration of GLP1 and leptin, but this was not the case in midbrain-transected rats. These findings imply that some signals produced by coinjection of GLP1 and leptin affect POMC neurons located in the arcuate nucleus via neural pathways from the hindbrain to the hypothalamus.

Previously, we have also shown that coinjection of subthreshold doses of GLP1 and leptin did not affect the mRNA expression of neuropeptide $Y$, agouti-related protein, or cocaine-and amphetamine-regulated transcript in the hypothalamic arcuate nucleus, whereas it significantly increased Pomc expression (Poleni et al. 2012). POMC is a precursor of $\alpha$-MSH, which, when released from the axon terminals of POMC neurons, binds to and activates MC4R, thereby reducing food intake and body weight (Huszar et al. 1997). In the adult rodent brain, the majority of POMC neurons are located in the hypothalamic arcuate nucleus (Cone 2005, Padilla et al. 2012). Therefore, although we did not investigate POMC expression here in our micro-dissection of the arcuate nucleus, we assumed that our data for the whole hypothalamus approximately reflected Pomc mRNA levels in the arcuate nucleus. We have also previously shown that central preadministration of MC4R antagonists blocks the effect of coinjection of GLP1 and leptin on food intake (Poleni et al. 2012). These findings indicate that coinjection of GLP1 and leptin ultimately reduces food intake via the POMC/MC4R system. We have shown here that the increase in Pomc mRNA expression after coinjection of GLP1 and leptin was blocked in midbraintransected rats. This result indicates that the satiety signals produced by coinjection of GLP1 and leptin affect the POMC/MC4R system in the hypothalamus via first-order neurons located in the hindbrain.

AMPK acts as a general energy sensor and integrator of nutrient or hormonal signals in the hypothalamus (Kahn et al. 2005, Ramamurthy \& Ronnett 2006). Hypothalamic AMPK activity is decreased by the action of anorectic hormones such as leptin (Andersson et al. 2004, Minokoshi et al. 2004), insulin (Kola 2008), or GLP1 (Seo et al. 2008). Furthermore, MC4R is involved in AMPK activity in the hypothalamus (Minokoshi et al. 2008). In this study, we have demonstrated that coinjection of subthreshold doses of GLP1 and leptin dramatically
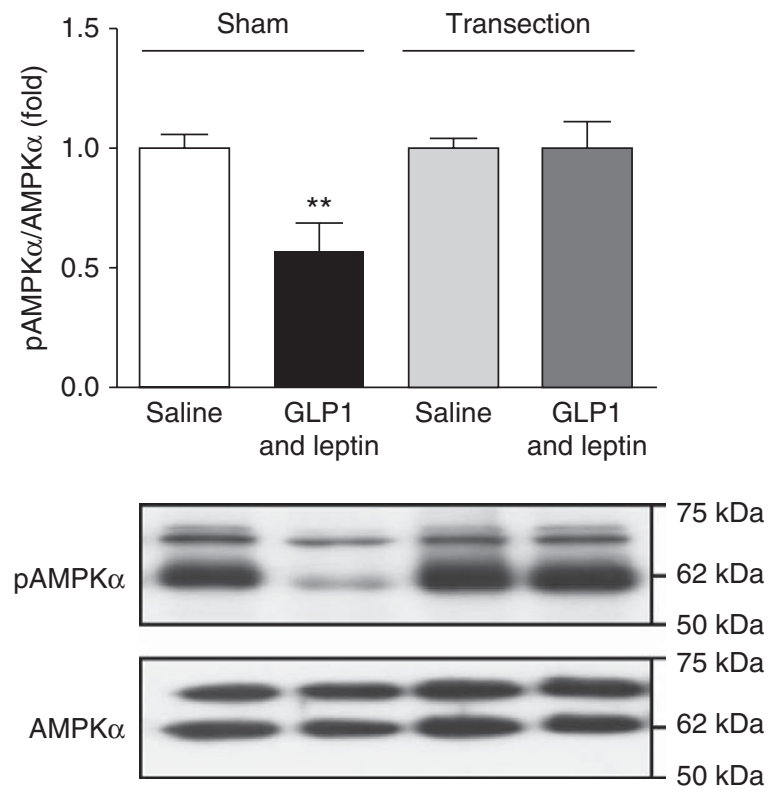

Figure 4

Western blot analysis of phosphorylated AMP-activated protein kinase (pAMPK) in the hypothalami of sham-operated rats and midbraintransected rats after i.p. administration of saline or of GLP1 $(10 \mathrm{nmol} / \mathrm{kg})$ and leptin $(18.8 \mathrm{nmol} / \mathrm{kg})$. The band intensity ratio of PAMPK to AMPK in sham-operated rats after saline administration was arbitrarily set as 1.0. Data represent means \pm S.E.M. ( $n=4$ each). ${ }^{* *} P<0.01$ vs sham-operated saline (one-way ANOVA followed by Tukey-Kramer test).

Published by Bioscientifica Ltd. 
decreased the phosphorylation of AMPK in the hypothalami of sham-operated rats, whereas this effect was blocked in midbrain-transected rats. Taken together, these findings show that the satiety signals provided by coinjection of GLP1 and leptin are transmitted, at least in part, via the neural pathway from the hindbrain to POMC neurons present in the arcuate nucleus, which in turn decrease the phosphorylation of AMPK through the POMC/MC4R system and thereby reduce food intake. Because $\mathrm{MC} 4 \mathrm{R}$ is expressed in various brain areas, including the paraventricular nucleus, lateral hypothalamus, and ventromedial nuclei, AMPK phosphorylation needs to be evaluated in these hypothalamic areas. However, some reports have shown that MC4R located in the paraventricular nucleus is essential for food intake regulation (Balthasar et al. 2005, Cone 2006). Therefore, we surmise that our data regarding levels of AMPK phosphorylation in the whole hypothalamus mainly reflect the levels in the paraventricular nucleus. To confirm this conjecture, we will need to evaluate the levels of phosphorylation of AMPK in a future micro-dissection study of the paraventricular nucleus.

We have shown here that various interactive effects of GLP1 and leptin in the reduction of food intake were blocked in midbrain-transected rats. Our findings imply that identifying the transmitters involved in conveying the interactive signals of GLP1 and leptin from the hindbrain to the hypothalamus, as well as elucidating the interactive mechanism of GLP1 and leptin in influencing AMPK, will advance our interpretation of the physiological roles of feeding-related hormones. Investigating the effect of repeated coinjections of GLP1 and leptin on food intake reduction or weight loss will be important as well. Our data will help to further understand the mechanisms of feeding and energy balance from the perspective of multifactorial regulatory systems that underlie functions such as neurohormonal integration.

\section{Declaration of interest}

The authors declare that there is no conflict of interest that could be perceived as prejudicing the impartiality of the research reported.

\section{Funding}

This study was supported in part by grants-in-aid for Scientific Research on Innovative Areas; the Program for Promotion of Basic Research Activities for Innovative Bioscience; the Mitsubishi Foundation; the Naito Foundation; and the Takeda Science Foundation.

\section{Acknowledgements}

The authors thank A Miyashita, Y Aiboshi, and T Miyanaga (University of Miyazaki) for their technical assistance and $\mathrm{N}$ Murakami (University of Miyazaki) for helpful discussions.

\section{References}

Andersson U, Filipsson K, Abbott CR, Woods A, Smith K, Bloom SR, Carling D \& Small CJ 2004 AMP-activated protein kinase plays a role in the control of food intake. Journal of Biological Chemistry 279 12005-12008. (doi:10.1074/jbc.C300557200)

Balthasar N, Dalgaard LT, Lee CE, Yu J, Funahashi H, Williams T, Ferreira M, Tang V, McGovern RA, Kenny CD et al. 2005 Divergence of melanocortin pathways in the control of food intake and energy expenditure. Cell 123 493-505. (doi:10.1016/j.cell.2005.08.035)

Bjorbaek C \& Kahn BB 2004 Leptin signaling in the central nervous system and the periphery. Recent Progress in Hormone Research 59 305-331. (doi:10.1210/rp.59.1.305)

Chan RK, Brown ER, Ericsson A, Kovacs KJ \& Sawchenko PE 1993 A comparison of two immediate-early genes, c-fos and NGFI-B, as markers for functional activation in stress-related neuroendocrine circuitry. Journal of Neuroscience 13 5126-5138.

Cone RD 2005 Anatomy and regulation of the central melanocortin system. Nature Neuroscience 8 571-578. (doi:10.1038/nn1455)

Cone RD 2006 Studies on the physiological functions of the melanocortin system. Endocrine Reviews 27 736-749. (doi:10.1210/er.2006-0034)

Crawley JN, Kiss JZ \& Mezey E 1984 Bilateral midbrain transections block the behavioral effects of cholecystokinin on feeding and exploration in rats. Brain Research 322 316-321. (doi:10.1016/ 0006-8993(84)90124-0)

Date Y, Ueta Y, Yamashita H, Yamaguchi H, Matsukura S, Kangawa K, Sakurai T, Yanagisawa M \& Nakazato M 1999 Orexins, orexigenic hypothalamic peptides, interact with autonomic, neuroendocrine and neuroregulatory systems. PNAS 96 748-753. (doi:10.1073/ pnas.96.2.748)

Date Y, Murakami N, Toshinai K, Matsukura S, Niijima A, Matsuo H, Kangawa K \& Nakazato M 2002 The role of the gastric afferent vagal nerve in ghrelin-induced feeding and growth hormone secretion in rats. Gastroenterology 123 1120-1128. (doi:10.1053/gast.2002.35954)

Date Y, Shimbara T, Koda S, Toshinai K, Ida T, Murakami N, Miyazato M, Kokame K, Ishizuka Y, Ishida Y et al. 2006 Peripheral ghrelin transmits orexigenic signals through the noradrenergic pathway from the hindbrain to the hypothalamus. Cell Metabolism 4 323-331. (doi:10.1016/j.cmet.2006.09.004)

Date Y, Mondal MS, Kageyama H, Ghamari-Langroudi M, Takenoya F, Yamaguchi H, Shimomura Y, Mori M, Murakami N, Shioda S et al. 2010 Neuropeptide $\mathrm{W}$ : an anorectic peptide regulated by leptin and metabolic state. Endocrinology 151 2200-2210. (doi:10.1210/en. 2009-1153)

Elias CF, Kelly JF, Lee CE, Ahima RS, Drucker DJ, Saper CB \& Elmquist JK 2000 Chemical characterization of leptin-activated neurons in the rat brain. Journal of Comparative Neurology 423 261-281. (doi:10.1002/ 1096-9861(20000724)423:2<261::AID-CNE6>3.0.CO;2-6)

Farooqi S, Rau H, Whitehead J \& O'Rahilly S 1998 ob gene mutations and human obesity. Proceedings of the Nutrition Society $\mathbf{5 7} 471-475$. (doi:10.1079/PNS19980067)

Hayes MR, De Jonghe BC \& Kanoski SE 2010 Role of the glucagon-likepeptide-1 receptor in the control of energy balance. Physiology \& Behavior 100 503-510. (doi:10.1016/j.physbeh.2010.02.029)

Holst JJ 2007 The physiology of glucagon-like peptide 1. Physiological Reviews 87 1409-1439. (doi:10.1152/physrev.00034.2006)

Hosoi T, Kawagishi T, Okuma Y, Tanaka J \& Nomura Y 2002 Brain stem is a direct target for leptin's action in the central nervous system. Endocrinology 143 3498-3504. (doi:10.1210/en.2002-220077) 
Huszar D, Lynch CA, Fairchild-Huntress V, Dunmore JH, Fang Q, Berkemeier LR, Gu W, Kesterson RA, Boston BA, Cone RD et al. 1997 Targeted disruption of the melanocortin- 4 receptor results in obesity in mice. Cell 88 131-141. (doi:10.1016/S0092-8674(00)81865-6)

Kahn BB, Alquier T, Carling D \& Hardie DG 2005 AMP-activated protein kinase: ancient energy gauge provides clues to modern understanding of metabolism. Cell Metabolism 1 15-25. (doi:10.1016/ j.cmet.2004.12.003)

Koda S, Date Y, Murakami N, Shimbara T, Hanada T, Toshinai K, Niijima A, Furuya M, Inomata N, Osuye Ket al. 2005 The role of the vagal nerve in peripheral PYY3-36-induced feeding reduction in rats. Endocrinology 146 2369-2375. (doi:10.1210/en.2004-1266)

Kola B 2008 Role of AMP-activated protein kinase in the control of appetite. Journal of Neuroendocrinology 20 942-951. (doi:10.1111/j.1365-2826. 2008.01745.x)

Leshan RL, Bjornholm M, Munzberg H \& Myers MG Jr 2006 Leptin receptor signaling and action in the central nervous system. Obesity 14(Suppl 5) 208S-212S. (doi:10.1038/oby.2006.310)

Minokoshi Y, Alquier T, Furukawa N, Kim YB, Lee A, Xue B, Mu J, Foufelle F, Ferre P, Birnbaum MJ et al. 2004 AMP-kinase regulates food intake by responding to hormonal and nutrient signals in the hypothalamus. Nature 428 569-574. (doi:10.1038/nature02440)

Minokoshi Y, Shiuchi T, Lee S, Suzuki A \& Okamoto S 2008 Role of hypothalamic AMP-kinase in food intake regulation. Nutrition $\mathbf{2 4}$ 786-790. (doi:10.1016/j.nut.2008.06.002)

Mojsov S, Heinrich G, Wilson IB, Ravazzola M, Orci L \& Habener JF 1986 Preproglucagon gene expression in pancreas and intestine diversifies at the level of post-translational processing. Journal of Biological Chemistry 261 11880-11889.

Munzberg H, Huo L, Nillni EA, Hollenberg AN \& Bjorbaek C 2003 Role of signal transducer and activator of transcription 3 in regulation of hypothalamic proopiomelanocortin gene expression by leptin. Endocrinology 144 2121-2131. (doi:10.1210/en.2002-221037)

Myers MG Jr, Munzberg H, Leinninger GM \& Leshan RL 2009 The geometry of leptin action in the brain: more complicated than a simple ARC. Cell Metabolism 9 117-123. (doi:10.1016/i.cmet.2008.12.001)
Padilla SL, Reef D \& Zeltser LM 2012 Defining POMC neurons using transgenic reagents: impact of transient Pomc expression in diverse immature neuronal populations. Endocrinology 153 1219-1231. (doi:10.1210/en.2011-1665)

Paxinos G \& Watson C 2005 The Rat Brain in Stereotaxic Coordinates. San Diego: Elsevier.

Pelleymounter MA, Cullen MJ, Baker MB, Hecht R, Winters D, Boone T \& Collins F 1995 Effects of the obese gene product on body weight regulation in ob/ob mice. Science 269 540-543. (doi:10.1126/ science.7624776)

Poleni PE, Akieda-Asai S, Koda S, Sakurai M, Bae CR, Senba K, Cha YS, Furuya M \& Date Y 2012 Possible involvement of melanocortin-4receptor and AMP-activated protein kinase in the interaction of glucagon-like peptide- 1 and leptin on feeding in rats. Biochemical and Biophysical Research Communications 420 36-41. (doi:10.1016/ j.bbrc.2012.02.109)

Ramamurthy S \& Ronnett GV 2006 Developing a head for energy sensing: AMP-activated protein kinase as a multifunctional metabolic sensor in the brain. Journal of Physiology 574 85-93. (doi:10.1113/jphysiol. 2006.110122)

Sagar SM, Sharp FR \& Curran T 1988 Expression of c-fos protein in brain: metabolic mapping at the cellular level. Science 240 1328-1331. (doi:10.1126/science.3131879)

Schwartz MW, Woods SC, Porte D Jr, Seeley RJ \& Baskin DG 2000 Central nervous system control of food intake. Nature $\mathbf{4 0 4} 661-671$. (doi:10.1038/35007534)

Seo S, Ju S, Chung H, Lee D \& Park S 2008 Acute effects of glucagon-like peptide- 1 on hypothalamic neuropeptide and AMP activated kinase expression in fasted rats. Endocrine Journal 55 867-874. (doi:10.1507/ endocri.K08E-091)

Stanley S, Wynne K, McGowan B \& Bloom S 2005 Hormonal regulation of food intake. Physiological Reviews 85 1131-1158. (doi:10.1152/physrev. 00015.2004)

Williams DL, Baskin DG \& Schwartz MW 2006 Leptin regulation of the anorexic response to glucagon-like peptide-1 receptor stimulation. Diabetes 55 3387-3393. (doi:10.2337/db06-0558)

Received in final form 18 October 2013

Accepted 12 November 2013

Accepted Preprint published online 12 November 2013
(C) 2014 Society for Endocrinology Printed in Great Britain 